\title{
STUDI TENTANG KONDUKTIVITAS DAN RESISTANSI TERMAL GEOPOLIMER BERPORI BERBASIS ABU TERBANG (FLY ASH)
}

\author{
*Sulfianty \\ Universitas Negeri Makassar \\ vivisulfianty27@gmail.com \\ Nurhayati \\ Universitas Negeri Makassar \\ nurhayati@unm.ac.id \\ Subaer \\ Universitas Negeri Makassar \\ subaer@unm.ac.id \\ *koresponden author
}

Abstrak - Telah dilakukan penelitian yang bertujuan untuk menyelidiki sifat konduktivitas dan resistansi termal geopolimer berbasis abu terbang. Pembuatan sampel dengan menambahkan agen pembentuk pori $\left(\mathrm{H}_{2} \mathrm{O}_{2}\right)$ ke dalam pasta geopolimer yang diaktivasi menggunakan alkali, dikeringkan (curing) pada suhu $70{ }^{\circ} \mathrm{C}$ selama 24 jam dan disimpan pada ruang terbuka selama \pm 3 hari. Pengujian awal meliputi pengujian porositas, massa jenis dan daya serap air sedangkan pengujian untuk sampel geopolimer berpori sesuai standar SNI 03-0349-1989 terdiri dari X-ray Diffraction, mikroskop optik digital, konduktivitas dan resistansi termal serta resistansi api dan panas (Shock thermal). Berdasarkan hasil penelitian dapat disimpulkan bahwa penambahan $\mathrm{H}_{2} \mathrm{O}_{2}$ memperbesar porositas dan daya serap air sehingga massa jenis menjadi semakin kecil. Sampel yang sesuai standar SNI 03-0349-1989 berdasarkan pengujian awal adalah sampel dengan komposisi 1,6\%. Hasil karakterisasi XRD menunjukan bahwa fase berbentuk amorf dengan intensitas tertinggi diperoleh oleh $\mathrm{SiO}_{2}$ dan hasil karakterisasi mikroskop optik digital menunjukan bahwa ukuran pori dari sampel tidak seragam berkisar antara 1-10 mm. Adapun hasil uji konduktivitas dan resistansi termal berturutturut yaitu $0,77 \mathrm{~W} / \mathrm{m} \mathrm{K}$ dan $0,02 \mathrm{~K} . \mathrm{m} 2 / \mathrm{W}$. Uji resistansi api dan panas (shock thermal) menunjukan bahwa sampel dapat bertahan hingga $1300^{\circ} \mathrm{C}$. Hal ini menunjukan bahwa geopolimer berpori berbahan dasar abu terbang (Fly Ash) memiliki nilai konduktivitas dan resistansi termal yang rendah dan tahan terhadap suhu tinggi sehingga dapat diaplikasikan sebagai bahan isolasi termal yang baik dan ramah lingkungan.

Kata Kunci : Konduktivitas Termal, Resistansi Termal, Geopolimer Berpori, $\mathrm{H}_{2} \mathrm{O}_{2}$.

\begin{abstract}
Research has been conducted which aims to investigate the nature of thermal conductivity and thermal resistance. Sampling is done by adding a pore forming agent $\left(\mathrm{H}_{2} \mathrm{O}_{2}\right)$ to an activated geopolymers paste using alkali, curing at $70^{\circ} \mathrm{C}$ for 24 hours and kept in an open space for 3 days. Initial testing includes testing porosity, density and water absorption while testing for porous geopolymers samples according to SNI 03-03491989 consist $f$ X-Ray diffraction, digital optical microscopy, thermal conductivity and thermal resistance as well as fire and heat resistance (Thermal shock). Based on the results of ther study it can be concluded that the addition of $\mathrm{H}_{2} \mathrm{O}_{2}$ will increase the porosity and absorption capacity so that the density will be smaller. Samples that comply with SNI 03-0349-1989 standard based on initial testing are samples with a composiion of $1,6 \%$. The XRD characterization result showed that the amorphous phase $w$ ith the highest intensity was obtained by $\mathrm{SiO}$, and the results of digital optical microscope characterization result showed that the pore size and samples were not uniformly ranged from 1-10 $\mathrm{mm}$. The results of concurrent conductivity and thermal resistance tests are yaitu $0,77 \mathrm{~W} / \mathrm{m} \mathrm{K}$ dan $0,02 \mathrm{~K} \cdot \mathrm{m}^{2} / \mathrm{W}$. As well as fire and heat resistance tests (thermal shock) shows that the sample can last up to $1300^{\circ} \mathrm{C}$. This shows that porous geopolymers made from fly ash (Fly Ash) have low conductivity and thermal resistance values and are resistant to high temperatures can be used as a good thermal insulation material and environmentally friendly.
\end{abstract}

Keywords : Thermal Conductivity, Thermal Resistance, Geopolymers Porous, $\mathrm{H}_{2} \mathrm{O}_{2}$. 


\section{A. PENDAHULUAN}

Perkembangan ilmu pengetahuan dan teknologi yang sangat pesat menyebabkan terjadinya berbagai permasalahan di bumi seperti pemanasan global yang berdampak pada meningkatnya temperatur bangunan rumah tinggal. Temperatur yang tinggi disebabkan oleh tidak adanya sirkulasi udara yang memadai atau penyerapan panas matahari oleh komponen dinding. Panas matahari yang mengenai dinding bangunan terserap, dan dengan cara radiasi dan konveksi dipancarkan ke dalam ruangan. Hal ini menimbulkan rasa tidak nyaman bagi penghuni bangunan (Pujiyanti, Fitriah, \& Darmawan, 2017). Kondisi inilah yang menuntut adanya material baru yang memiliki sifat yang lebih baik dari material sebelumnya.

Sifat-sifat material yang paling penting untuk dipelajari terbagi menjadi beberapa aspek yaitu aspek mekanik, optik, listrik, magnetik, daya tahan terhadap lingkungan fisik atau kimia, dan termal. Sifat termal adalah sifat yang menunjukan respon material terhadap panas yang diterima. Salah satu material yang memiliki sifat termal yang baik dan ramah lingkungan adalah geopolimer berpori (leping, Xue-min, Shu-heng, Jun-lie, \& Lin, 2010).

Geopolimer berpori adalah geopolimer yang memiliki massa ringan disebabkan karena adanya rongga udara yang terjebak, dalam matriks (Hajimohammadia, TuanNgoa, Mendisa, \& Sanjayan, 2017). Geopolimer berpori memiliki stabilitas termal, sifat kimia dan sifat mekanik yang sangat baik, penggunaan energi yang rendah pada saat proses pembuatan, serta emisi $\mathrm{CO}_{2}$ yang rendah dibandingkan semen portland karena sifatnya yang ramah lingkungan (Bai \& Colombo, 2018). Sama halnya dengan geopolimer biasa, geopolimer berpori dapat diproduksi dengan mensintesis bahan alam seperti metakaolin-lempung atau produk industri sampingan seperti fly ash (Huang, Gong, Shi, Cao, Pan, \& Cheng, 2018) Fly Ash adalah produk sampingan yang dihasilkan dari proses pembakaran batu bara. Proses pembakaran batu bara ini menghasilkan Fly Ash dalam jumlah yang sangat besar dan tergolong limbah B3. Pembuangan limbah B3 dari Fly Ash diketahui dapat menimbulkan bahaya bagi kehidupan manusia (Böke, Birch, Nyale, \& Petrik, 2015). Salah satu cara untuk mengurangi bahaya tersebut yaitu dengan memanfaatkan fly ash sebagai bahan dasar sintesis geopolimer (Huang, Gong, Shi, Cao, Pan, \& Cheng, 2018).

Geopolimer berpori berbasis Fly ash disintesis dengan foam method seperti menambahkan bubuk aluminium dan hidrogen peroksida. Hidrogen peroksida $\left(\mathrm{H}_{2} \mathrm{O}_{2}\right)$ menunjukan kinerja yang relatif baik dibandingkan agen berbusa yang lain (Huang, Gong, Shi, Cao, Pan, \& Cheng, 2018). $\mathrm{H}_{2} \mathrm{O}_{2}$ dipilih sebagai agen berpori karena mudah terurai menjadi $\mathrm{H}_{2} \mathrm{O}$ dan $\mathrm{O}_{2}$ dan menciptakan pori pada geopolimer. Hidrogen peroksida $\left(\mathrm{H}_{2} \mathrm{O}_{2}\right)$ memiliki ciri-ciri oksidator kuat, tidak berwarna, memiliki bau yang khas dan sedikit asam. $\mathrm{H}_{2} \mathrm{O}_{2}$ mempunyai sifat yang larut dalam air, stabil dalam kondisi normal dan laju dekomposisi yang sangat rendah (Ella Kusumastuti, 2015). Berdasarkan latar belakang tersebut, maka dikembangkan penelitian untuk mempelajari sifat termal dari geopolimer berpori dengan bahan dasar fly ash dan $\mathrm{H}_{2} \mathrm{O}_{2}$ sebagai agen pembentuk pori. 


\section{B. METODE}

Penelitian ini merupakan penelitian eksperimental murni. Penelitian ini dilakukan di laboratorium Fisika Material Universitas Negeri Makassar untuk menyelidiki sifat konduktivitas termal dan resistansi termal sampel geopolimer berpori berbasis abu terbang (Fly Ash).

a) Pembuatan Sampel Geopolimer Berpori

Pasta geopolimer berpori disintesis dengan menggunakan abu terbang (fly ash) yang diaktifkan dengan larutan alkali sampai terbentuk pasta geopolimer. Kemudian ditambahkan agen pembentuk pori yaitu hidrogen peroksida ke dalam pasta geopolimer yang tadi. Selanjutnya mencetak pasta geopolimer berpori pada cetakan yang telah dibuat. Sampel yang sudah dicetak dibiarkan pada suhu kamar, kemudian di-curing pada oven dengan suhu rendah pada temperature $70^{\circ} \mathrm{C}$ selama 24 jam sehingga proses polikondensasi sempurna dapat tercapai. Kemudian melepaskan Sampel yang telah di-curing setelah berusia 3 hari dari cetakan. Ukuran dan bentuk sampel disesuaikan dengan kebutuhan pengukuran dan karakterisasi.

b) Pengujian Dasar

Pengujian dasar dalam penelitian ini dimaksudkan untuk mencari komposi yang sesuai standar SNI 03-0349-1989 dimana porositas diatas 30\% dan massa jenis lebih rendah dari $1 \mathrm{gr} / \mathrm{cm}$ (Anonim, 1989). Pengujian ini terdiri dari 3 jenis yaitu pengukuran porositas, massa jenis dan daya serap air.

1. Porositas dan massa Jenis

Pengujian massa jenis dan porositas sampel geopolimer dilakukan dengan menggunakan metode Archimedes dan menghitung nilai porositas dan massa jenis dengan menggunakan rumus sebagai berikut:

$$
D_{b}=\frac{m_{d}}{m_{s}-m_{i}} \times D_{i} \quad \text { (1) } P_{a}=\frac{m_{s}-m_{d}}{m_{s}-m_{i}} \times 100 \%
$$

Dengan $D_{b}$ menyatakan rapat massa, $m_{d}$ menyatakan massa geopolimer kering, $m_{i}$ massa geopolimer jenuh air dan disuspensi udara di dalam air, $m_{s}$ massa geopolimer jenuh air dan disuspensi di udara, $D_{i}$ massa jenis air pada temperatur kamar dan $P_{a}$ menyatakan porositas (Subaer, 2015)

\section{Daya Serap Air}

Pengujian daya serap air dilakukan untuk mengetahui kemampuan geopolimer berpori dalam menyerap dan menyimpan air. Cara pengujian daya serap air yaitu merendam sampel ke dalam baskom yang telah berisi air selama kurang lebih 24 jam. Setalah itu sampel di keluarkan dari dalam baskom kemudian di biarkan menetes hingga 1 menit (A). Hasil Perhitungan nilai daya serap untuk setiap sampel dapat dianalisis dengan persamaan berikut: 


$$
\mathrm{C}=\frac{(A-B)}{B} \times 100 \%
$$

Berat basah (A) merupakan berat setelah direndam dalam keadaan bersih selama \pm 24 jam, kemudian diangkat dari air dan air sisanya dibiarkan menetes \pm 1 menit, lalu diseka permukaan dengan kain untuk menghilangkan kelebihan air masih tertinggal. Berat kering (B) yaitu berat setelah dikeringkan dan C adalah penyerapan air.

c) Pengujian Sampel Geopolimer Berpori yang sesuai standar SNI 03-0349-1989

Sampel yang terpilih pada pengujian awal (komposisi $1,6 \% \mathrm{H}_{2} \mathrm{O}_{2}$ ) akan dilanjutkan pada pengujian ini yaitu terdiri dari 4 jenis pengujian yaitu X-Ray Diffraction (XRD, mikroskop optik diital, konduktivitas dan resistansi terrmal serta Resistansi api dan panas (Shock Thermal).

\section{X-Ray Difraction (XRD)}

Karakterisasi XRD dilakukan untuk mengetahui struktur kristal dan kandungan senyawa dari sampel geopolimer berpori yang selanjutnya digunakan untuk memperkuat informasi tentang karakteristik sampel yang terpilih. Karakterisasi XRD menggunakan X-ray difractometer merek Rikagu tipe miniflex II (Radiasi $\mathrm{Cu} \mathrm{K \alpha}, \lambda=1,54056 \mathrm{~A}$ ) dengan sudut operasi $2 \theta=10^{\circ}-70^{\circ}$.

\section{Mikroskop Optik Digital}

Mikroskop optik digital yang digunakan adalah mikroskop yang dilengkapi LED dan USB yang terhubung dengan laptop dan software Coolingtech. Observasi ini dilakukan untuk melihat morfologi dan ukuran pori dari sampel geopolimer berpori.

\section{Konduktivitas dan Resistansi Termal}

Pengukuran konduktivitas termal bertujuan mengetahui kemampuan sampel dalam menghantarkan panas. Metode yang digunakan dalam pengukuran konduktivitas termal adalah metode hot plate. Persamaan yang digunakan untuk menghitung nilai konduktivitas dan resistansi termal adalah persamaan fourier sebagai berikut:

$$
\begin{aligned}
& k=\frac{Q}{A} \times \frac{d X}{d T} \\
& R=\frac{\Delta T}{q}=\frac{L}{k}
\end{aligned}
$$

Besaran ini didefinisikan sebagai $q_{k}$ menyatakan laju aliran panas secara konduksi (Watt), $\mathrm{k}$ 
adalah konduktivitas bahan $(\mathrm{W} / \mathrm{mK})$, A menyatakan luas penampang $\left(\mathrm{m}^{2}\right)$ dan $\frac{d T}{d x}$ menyatakan gradien suhu pada penampang $(K)$. R menyatakan resistansi termal, $\Delta T$ menyatakan perubahan suhu, $\mathrm{q}$ menyatakan kalor, L menyatakan tebal sampel dan $\mathrm{k}$ menyatakan nilai konduktivtas termal (Chapman, 1984)

\section{Resistansi Api dan Panas (Shock Thermal)}

Pengujian shock termal dilakukan untuk mengetahui kemampuan suatu material untuk menahan panas yang diberikan. Pengujian ini dilakukan dengan menggunakan alat pemetik api (torcher) dengan suhu $1300^{\circ} \mathrm{C}$.

\section{HASIL DAN PEMBAHASAN}

Pengukuran porositas dan massa jenis pada penelitian ini bertujuan untuk melihat perubahan yang terjadi ketika diberikan hidrogen peroksida sekaligus sebagai pengujian dasar untuk mencari satu sampel yang memenuhi kriteria.

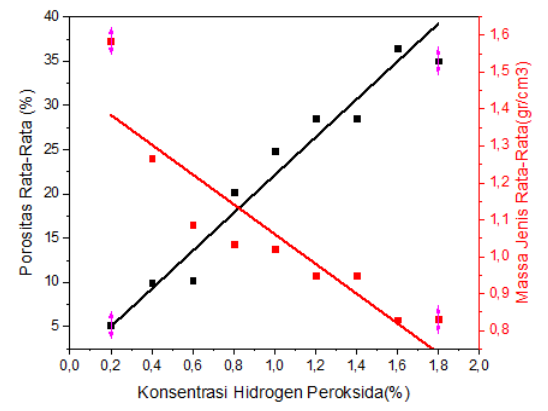

Gambar 1 Hubungan Antara Konsentrasi $\mathrm{H}_{2} \mathrm{O}_{2}(\%)$ Dengan Porositas dan massa jenis rata-rata sampel

Geopolimer Berpori

Berdasarkan gambar 1 terlihat bahwa nilai porositas dan massa jenis rata-rata geopolimer berpori dengan variasi penambahan hidrogen peroksida $\left(\mathrm{H}_{2} \mathrm{O}_{2}\right)$. Berdasarkan grafik tersebut dapat disimpulkan bahwa semakin banyak hidrogen peroksida $\left(\mathrm{H}_{2} \mathrm{O}_{2}\right)$ yang di tambahkan pada pasta geopolimer maka porositas akan semakin bertambah. Hal ini berdampak pada nilai massa jenis geopolimer berpori yang semakin menurun. Hal ini sesuai dengan penelitian yang dilakukan oleh (Seabra, Labrinca, Novais, Buruberi, \& Ascens, 2016) dan (Abdollahnejada, Pacheco-Torgala, Félixb, Tahric, \& Aguiar, 2015) yang menyatakan bahwa peningkatan kadar agen pembentuk pori menyebabkan terjadinya peningkatan jumlah porositas dan menurunkan nilai massa jenis suatu material dalam hal ini geopolimer berpori.

Pengujian daya serap air dalam penelitian ini bertujuan untuk mengetahui kekuatan daya serap air geopolimer berpori pada setiap penambahan konsentrasi hidrogen peroksida $\left(\mathrm{H}_{2} \mathrm{O}_{2}\right)$. Gambar 2 merupakan grafik hubungan antara penambahan konsentrasi hidrogen peroksida $\left(\mathrm{H}_{2} \mathrm{O}_{2}\right)$ terhadap nilai 
daya serap air rata-rata dari sampel geopolimer berpori. Peningkatan nilai daya serap air rata-rata dari sampel geopolimer berpori.

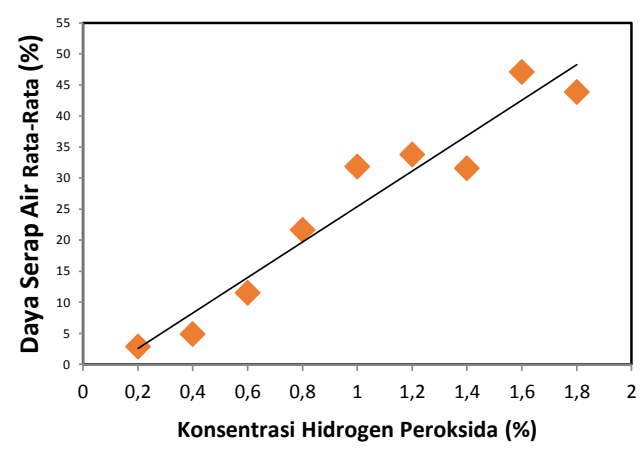

Gambar 2 Hubungan Antara Penambahan Konsentrasi $\mathrm{H}_{2} \mathrm{O}_{2}(\%)$ Dengan Daya Serap Air Rata-Rata Geopolimer Berpori $(\%)$

Berdasarkan gambar 2 dapat disimpulkan bahwa penambahan konsentrasi hidrogen peroksida $\left(\mathrm{H}_{2} \mathrm{O}_{2}\right)$ sangat berpengaruh terhadap nilai kekuatan daya serap air yakni semakin besar konsentrasi hidrogen peroksida maka semakin besar pula kekuatan daya serap airnya. Hal ini dikarenakan banyaknya ruang-ruang kosong dalam sampel yang membuat air akan mudah masuk kedalam.

A. Analisis Sampel Geopolimer Berpori yang sesuai standar SNI 03-0349-1989

1. X-Ray Diffraction (XRD)

Karakterisasi XRD digunakan untuk menganalisis fasa dan struktur kristal pada geopolimer berpori.

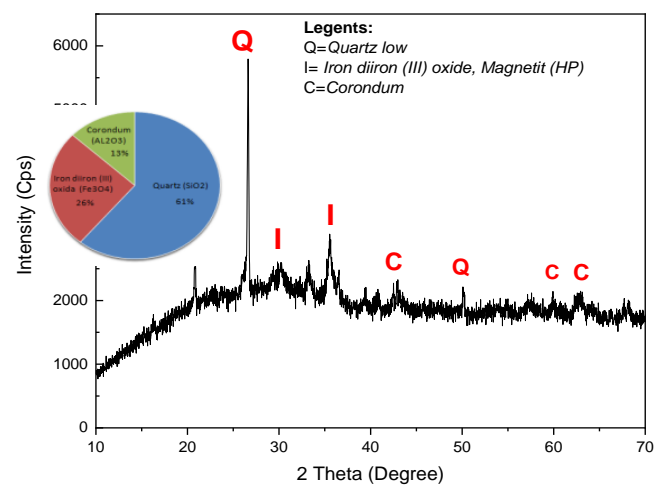

Gambar 3. Difraktogram geopolimer berpori

Dari gambar tersebut dapat dilihat bahwa fase yang terbentuk amorf dibuktikan dengan adanya hump atau gundukan yang lebar pada $2 \theta$ antara $10^{\circ}$ dan $40^{\circ}$ pada intensitas tertinggi di tunjukan oleh fase 
silika $\left(\mathrm{SiO}_{2}\right)$ yang bersifat quartz berada pada rentang sudut 2 theta $20^{\circ}-27^{\circ}$. Pada sudut sekitar $30^{\circ}-35^{\circ}$ terlihat fase iron serta sudut $43^{\circ}$ terlihat fase corondum. Kehadiran unsur-unsur ini diindikasikan berasal dari bahan dasar fly ash yang mendominasi unsur $\mathrm{SiO}_{2}, \mathrm{Fe}_{2} \mathrm{O}_{3}, \mathrm{Al}_{2} \mathrm{O}_{3}$ walaupun intensitasnya berbeda. Unsur-unsur dari agen pembentuk pori dalam hal ini adalah hidrogen peroksida tidak tampak pada analisis XRD disebabkan karena terjadi proses penguapan pada saat curing.

\section{Mikroskop Optik Digital}

Karakterisasi mikroskop optik digital di lakukan untuk mengetahui struktur morfologi sampel geopolimer berpori. Berikut adalah citra mikroskop optik sampel geopolimer berpori dengan konsentrasi $\mathrm{H}_{2} \mathrm{O}_{2}$ sebesar 1,6\%.

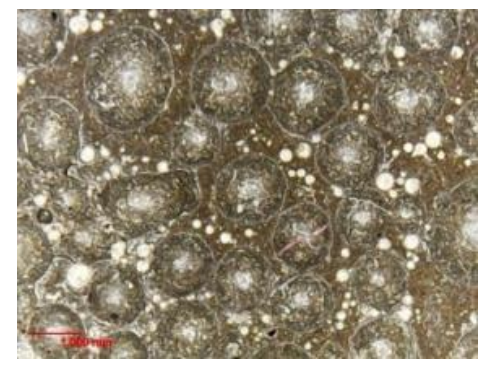

(a)

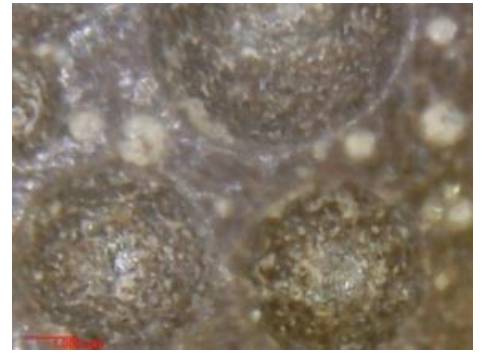

(b)

Gambar 4. Citra mikroskop Optik Digital sampel geopolimer berpori dengan perbesaran masing-masing (a) 40x, (b)1000x

Hasil analisis citra mikroskop optik menunjukan bahwa diameter pori berkisar $1 \mathrm{~mm}-10 \mathrm{~mm}$ dan struktur material yang teramati tidak homogen, artinya pori-pori terdistribusi tidak merata dan ukuran pori yang bervariasi. Hal ini disebabkan karena pencampuran dilakukan secara manual seperti yang dilaporkan oleh (Bai \& Colombo, 2018) bahwa struktur berpori ditentukan oleh beberapa jenis yaitu agen pembentuk pori, jumlah agen pembentuk pori, agen stabilisasi, viskositas bubur, komposisi geopolimer, dan kecepatan pencampuran.

3. Konduktivitas dan Resistansi Termal

Pengujian konduktivitas dan resistansi termal dilakukan untuk mengetahui kemampuan sampel dalam menghantarkan dan menahan panas. 
Tabel 1 Hasil analisis pengujian konduktivitas termal

\begin{tabular}{lcc}
\hline No & $\begin{array}{c}\text { Konduktivitas } \\
\text { Termal(W/m.K })\end{array}$ & $\begin{array}{c}\text { Resistansi } \\
\text { Termal } \\
\left(\mathrm{m}^{2} . \mathrm{K} / \mathrm{W}\right)\end{array}$ \\
\hline 1. & 0,99 & 0,02 \\
2. & 0,72 & 0,03 \\
3. & 0,61 & 0,03 \\
\hline Rata-rata & $|0,8 \pm 1,5|$ & $|0,02 \pm 0,01|$ \\
& &
\end{tabular}

Tabel 1 menunjukan bahwa nilai konduktivitas dan resistansi termal sampel geopolimer berpori dengan penambahan $1,6 \%$ hidrogen peroksida berturut-turut adalah $0,8 \mathrm{~W} / \mathrm{m} . \mathrm{K}$ dan $0,02 \mathrm{~m}^{2} . \mathrm{K} / \mathrm{W}$. Hasil yang diperoleh dari penelitian ini sesuai dengan hasil yang diperoleh oleh (Bai \& Colombo, 2018) dan (Zhang, Provis, Reid, \& Wang, 2014) yang mengatakan bahwa nilai konduktivitas termal sampel geopolimer berpori berkisar antara 0,16\%-1,067\% dengan porositas total sebesar 30\%-70\%. Hasil tersebut menunjukan bahwa sampel geopolimer berpori mempunyai konduktivitas termal yang rendah. Hal tersebut disebabkan banyaknya rongga/pori pada sampel sehingga menghambat proses perpindahan panas. Menurut (Bai \& Colombo, 2018) bahan yang memiliki konduktivitas rendah dapat digunakan untuk aplikasi dinding internal, ubin-ubin langit, membran, adsorben dan filter, katalis, akustik, serta bahan isolasi termal lainnya.

\section{Resistansi Api dan Panas (Shock Thermal)}

Pengujian Shock Thermal dimaksudkan untuk mengetahui daya tahan sampel ketika diberikan panas. Berikut adalah grafik hasil pengujian shock thermal.

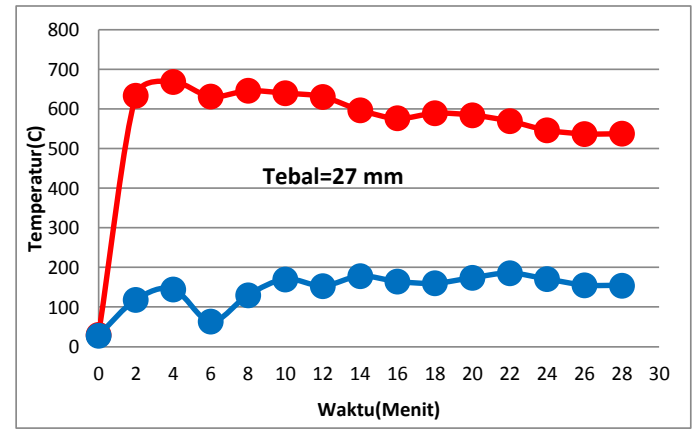

Gambar 5. Hasil Pengujian Resistansi Api dan Panas (Shock Thermal) 


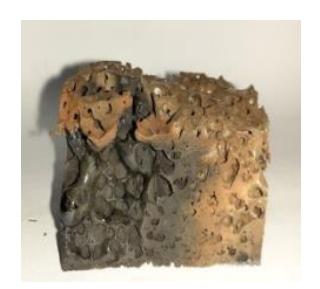

(a)

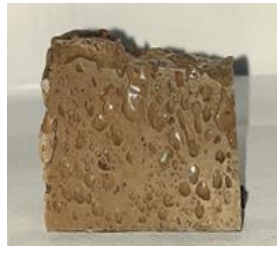

(b)

Gambar 6 Gambar permukaan sampel (a) sisi depan dan (b) sisi belakang

Gambar 5 dan 6 menyajikan hasil uji shock thermal sampel geopolimer berpori dengan komposisi 1,6\% dan ketebalan sampel sebesar 2,7 cm. Gambar 5 menunjukan grafik hubungan antara temperatur pada bagian depan (T1) dengan temperatur pada bagian belakang (T2) sedangkan gambar 6 adalah foto permukaan sampel geopolimer berpori setelah terpapar suhu $1300^{\circ} \mathrm{C}$ selama 30 menit. Dapat dilihat bahwa perbedaan suhu antara kedua permukaan sampel cukup besar yaitu sekitar $450^{\circ} \mathrm{C}$ dan setelah paparan permukaan sampel tidak diamati adanya kerusakan yang cukup fatal di area lain yang tidak langsung terpapar. Hasil yang diperoleh dalam penelitian ini hampir sama dengan hasil yang diperoleh oleh (Michal Lach, 2018) yaitu sampel yang dibuat memiliki tebal $45 \mathrm{~mm}$ dan $100 \mathrm{~mm} \mathrm{~mm}$ dengan perbedaan suhu kedua permukaan masing-masing $800^{\circ} \mathrm{C}$ dan $1000^{\circ} \mathrm{C}$ yang artinya semakin tebal sampel geopolimer berpori maka semakin besar perbedaan suhu antara kedua permukaan. Hal ini menunjukan bahwa sampel dapat digolongkan sebagai isolator panas yang cukup baik.

\section{SIMPULAN}

Kesimpulan yang dapat ditarik dari penelitian ini sebagai berikut

a. Nilai konduktivitas dan resistansi termal geopolimer berpori yang memenuhi standar SNI 03-0349$1989(\mathrm{~Pa} \geq 30 \%)$ berturut-turut adalah $0,77 \mathrm{~W} / \mathrm{m} . \mathrm{K}$ dan $0,02 \mathrm{~m}^{2} . \mathrm{K} / \mathrm{W}$ dan dapat digunakan untuk dinding termal, ubin-ubin langit, membran, adsorba dan filter, katalis akustik, dan bahan isolasi termal lainnya.

b. Hasil pengujian resistansi api dan panas (shock thermal) menunjukan bahwa sampel geopolimer berpori yang memenuhi standar SNI 03-0349-1989 (Pa $\geq 30 \%)$ tahan terhadap suhu sekitar $1300^{\circ} \mathrm{C}$ dan cocok di aplikasikan sebagai bahan tahan api.

\section{DAFTAR RUJUKAN}

Abdollahnejada, Z., Pacheco-Torgala, F., Félixb, T., Tahric, W., \& Aguiar, J. B. (2015). Mix design, properties and cost analysis of fly ash-based geopolymerfoam. Construction and Building Materials , 18-30.

Anonim. (1989). Bata beton untuk pasangan dinding. Badan Standarisasi Nasional Indonesia. 
Bai, C., \& Colombo, P. (2018). Processing, properties and applications of highlyporous geopolymers: a review. Ceramics International .

Böke, N., Birch, G. D., Nyale, S. M., \& Petrik, L. F. (2015). New synthesis method for the production of coal fly ash-based foamedgeopolymers. Construction and Building Materials, 189-199.

Chapman, A. J. (1984). Heat Transfer. New York: Library Of Congress Catalog.

Ella Kusumastuti, N. W. (2015). Sintesis Geopolimer Berbusa Berbahan Dasar Abu Layang Batubara Dengan Hidrogen Peroksida Sebagai Foaming Agent. Sainsteknol .

Hajimohammadia, A., TuanNgoa, Mendisa, P., \& Sanjayan, J. (2017). Regulating the chemical foaming reaction to control the porosity ofgeopolymer foams. Materials and Design , 255-265.

Huang, Y., Gong, L., Shi, L., Cao, W., Pan, Y., \& Cheng, X. (2018). Experimental investigation on the influencing factors of preparingporous fly ash-based geopolymer for insulation material. Energy \& Buildings .

le-ping, 1., Xue-min, C., Shu-heng, Q., Jun-lie, Y., \& Lin, Z. (2010). Applied Clay Science Preparation of phosphoric acid-based porous geopolymers. Applied Clay Science , 600-603.

Michal Lach, D. M. (2018). Geopolymer foam as a passive fire protection. MATEC Web of Conferences , 247.

Pujiyanti, I., Fitriah, T. A., \& Darmawan, I. (2017). Alterntif Teknik Passive Coolingyang Efisien Pada Ruang Auditorium Gedung B Universitas 'Aisyiyah Yogyakarta'. Jurnal Arsitektur dan Perencanaan, 1-13.

Seabra, M. P., Labrinca, J. A., Novais, R. M., Buruberi, L. H., \& Ascens, G. (2016). Porous biomass fl $\mathrm{y}$ ash-based geopolymers with tailored thermal conductivity.

Subaer. (2015). Pengantar Fisika Geopolimer. Makassar: Direktoral Jendral Pendidikan Tinggi

Zhang, Z., Provis, J. L., Reid, A., \& Wang, H. (2014). Geopolymer foam concrete : An emerging material for sustainable construction. Construction and Building Materials , 113-127.

Subaer. (2015). Pengantar Fisika Geopolimer. Makassar: Direktorat Jendral Pendidikan Tinggi 